SECTION 31. Economic research, finance, innovation.

Naumov Anatoly Aleksandrovich

Docent, Candidate of Technical Sciences, Center of Applied Mathematical Research, Novosibirsk, Russia,

E-mail: A_A_Naumov@mail.ru

\title{
SOME PROBLEMS OF CLASSICAL METHODS OF ECONOMIC SYSTEMS ANALYSIS AND WAYS OF THEIR PERMITS
}

Abstract: The paper discusses the problems of the classical methods of analysis of economic systems. In particular, such problem is well known ABC-analysis method. It is shown that the use of flow models for economic systems can improve the quality analysis methods for solving problems of management accounting.

Key words: Analysis of economic systems, management accounting, ABC-analysis, business processes, flow models, management, decision-making.

\section{УДК 330.46:330.322.5: 658.155}

\section{О ПРОБЛЕМАХ НЕКОТОРЫХ КЛАССИЧЕСКИХ МЕТОДОВ АНАЛИЗА ЭКОНОМИЧЕСКИХ СИСТЕМ И ПУТЯХ ИХ РАЗРЕШЕНИЯ}

Аннотация: В работе рассмотрены проблемы классических методов анализа экономических систем. В частности, такие проблемы имеет хорошо известный метод АВС-анализа. Показано, что использование потоковых моделей для экономических систем позволяет улучшить качество методов анализа для решения задач управленческого учета.

Ключевые слова: Анализ экономических систем, управленческий учет, АВСанализ, бизнес-процессы, потоковые модели, управление, принятие решений.

К написанию этой работы и проведению исследований в области проблем классических методов анализа экономических систем (ЭС) нас подвигли работы [1; 2]. Теория ограничений (Theory of Constraints, TOC) возникла в ответ на проблемы некоторых моделей анализа в управленческом учете. В частности, было показано, что методы $A B C$-анализа могут приводить к ошибочным решениям при управлении ЭС.

Рассмотрим пример из [1].

В компании имеется два станка: один служит для раскроя материала, а второй для пошива рубашек (мужских и женских). Женская рубашка требует для раскроя две минуты и пятнадцать минут для пошива, мужская рубашка - по десять минут на каждую операцию. В табл. 1 (см. [1], с. 22) приведены данные для рубашек двух типов.

Таблица 1

Данные для продукции компании двух видов

\begin{tabular}{|c|c|c|}
\hline & Женская & Мужская \\
\hline Спрос в неделю & 120 & 120 \\
\hline Цена & 105 & 100 \\
\hline Стоимость сырья & 45 & 50 \\
\hline Время раскроя & 2 & 10 \\
\hline Время пошива & 15 & 10 \\
\hline
\end{tabular}




\section{\begin{tabular}{|l|l|l|}
\hline Общее время производства & 17 & 20 \\
\hline
\end{tabular}}

Каждый из станков обслуживается одним рабочим. Время работы каждого из них - пять дней в неделю по восемь часов в день (2400 мин. в неделю). Время на каждую из операций приведено в табл. 2 (см. [1]). Операционные затраты компании составляют 10500 долларов в неделю (аренда, энергозатраты, зарплата и др.). Требуется определить, какой ассортимент максимизирует прибыль компании.

Таблица 2

\section{Затраты времени на каждую операцию}

\begin{tabular}{|c|c|c|c|c|}
\hline Операция & $\begin{array}{c}\text { Время на } \\
\text { женск. } \\
\text { рубашку, } \\
\text { мин. }\end{array}$ & $\begin{array}{c}\text { Время на } \\
\text { мужск. } \\
\text { рубашку, } \\
\text { мин. }\end{array}$ & $\begin{array}{c}\text { Общее } \\
\text { необходимое } \\
\text { время, мин. }\end{array}$ & $\begin{array}{c}\text { Необходимое } \\
\text { время/Доступное } \\
\text { время, \% }\end{array}$ \\
\hline Раскрой & 240 & 1200 & 1440 & $60 \%$ \\
\hline Пошив & 1800 & 1200 & 3000 & $125 \%$ \\
\hline
\end{tabular}

Найдем наиболее прибыльный товар в соответствии с теорией затрат. Для этого составим табл. 3 [1].

\section{Затраты на производство в денежном выражении}

Таблица 3

\begin{tabular}{|c|c|c|c|}
\hline & $\begin{array}{c}\text { Женская } \\
\text { рубашка }\end{array}$ & $\begin{array}{c}\text { Мужская } \\
\text { рубашка }\end{array}$ & $\begin{array}{c}\text { Лучший } \\
\text { продукт }\end{array}$ \\
\hline Цена & 105 долл. & 100 долл. & Женская \\
\hline Сырье & 45 долл. & 50 долл. & Женская \\
\hline $\begin{array}{c}\text { Время } \\
\text { производства }\end{array}$ & 17 мин. & 20 мин. & Женская \\
\hline
\end{tabular}

В соответствии с результатами анализа затрат наилучший вариант для ассортимента таков: 120 женских рубашек и 60 мужских рубашек. Найдем прибыль для такого плана выпуска (см. табл. 4).

\section{Расчет прибыли для ассортимента «120-60»}

Таблица 4

\begin{tabular}{|c|c|}
\hline & Доллары \\
\hline Выручка & 18600 \\
\hline Затраты на сырье & 8400 \\
\hline Валовая маржа & 10200 \\
\hline Операционные затраты & -10500 \\
\hline Чистая прибыль & -300 \\
\hline
\end{tabular}

Для второго варианта ассортимента (неоптимального с точки зрения теории затрат) - 80 женских рубашек и 120 мужских рубашек - чистая прибыль составит 300 долл. Метод затрат не позволил найти тот продукт, который наиболее всего способствует росту прибыли!

Что показывают этот и другие аналогичные примеры (см. работы [1; 2] и др.)? Во-первых, классические методы анализа ЭС имеют существенные недостатки. Вовторых, это еше раз подчеркивает тот факт, что от того, какой моделью пользуются для 
проведения анализа, будет зависеть результат этого анализа и принимаемых в соответствии с ним решений. В-третьих, для повышения эффективности проведения анализа и управления ЭС можно воспользоваться потоковыми моделями бизнеспроцессов (см., например, [3]), поскольку в них достаточно хорошо и подробно представлены все финансовые и ресурсные потоки. Кроме этого, в них представлена динамика изменения этих потоков во времени, что позволяет проводить анализ динамических характеристик ЭС. В-четвертых, для нахождения оптимальных стратегий развития ЭС необходимо решать оптимизационные задачи с использованием аппарата активных ограничений и так называемой теории расшивки узких мест. Анализ активных ограничений позволяет находить такие места в ЭС. В-пятых, методы управления ЭС примут целостный характер, если будут задействованы все элементы цепи обратной связи в контуре управления: блок «Модель ЭС», блок «Анализ ЭС», блок «Управление ЭС» [3]. Причем, хорошо известно, что от качества используемой модели ЭС будут зависеть как результаты проводимого анализа, так и принимаемое решение для управления ЭС.

Так, например, потоковая модель для ЭС в виде бизнес-процессов $\operatorname{Proc}_{f, i}(t)$, $i=1,2, \ldots, N$, может быть такой:

$$
\operatorname{Proc}_{f, i}(t)=\left\langle W_{f, i}(t), R_{f, i}(t), P_{f, i}(t), C_{f i n, i}(t), C_{\text {fout }, i}(t)\right\rangle, i=1,2, \ldots, N,
$$

здесь $W_{f, i}(t)$ - вектор потоков работ процесса; $R_{f, i}(t)$ - вектор ресурсов, расходуемых процессом; $C_{f i n, i}(t)$ - вектор входных (затратных) финансовых потоков процесса; $C_{\text {fout,i }}(t)$ - вектор выходных (доходных) финансовых потоков; $P_{f, i}(t)$ - вектор выпущенных (произведенных) продуктов (изделий, товаров, услуг и т.д.) процессом. В случае необходимости, в описание процессов $\operatorname{Proc}_{f, i}(t), i=1,2, \ldots, N$ могут быть введены и другие потоки.

Для моделей в таком виде могут быть использованы в качестве критериев эффективности критерии $N F V, N F V_{D F}$, IRR $R_{N F V}$ и многие другие (см. [3]). Кроме этого, в этом случае можно воспользоваться такими методами анализа ЭС, как анализ на чувствительность и устойчивость, проводить анализ рисков ЭС, факторный анализ и т.д. Опираясь на эти модели, можно оценить доходы интегрированных проектов, т.е. найти те части общего дохода, которые приходятся на каждый из частных проектов. Эта задача представляется очень важной, поскольку от ее корректного решения будет зависеть заинтересованность (или незаинтересованность) отдельных потенциальных участников в интеграционном процессе. Заметим, что метод детализации потоков позволяет наполнить задачу анализа ЭС и проектов практическим содержанием. В случае использования этого метода уточняются инвестиционные потоки (в них выделяются и конкретизируются собственно инвестиции в проект, схемы расчета с заемщиками по кредитам, схемы заимствования финансовых средств и т.д.) и потоки доходов (они расщепляются на доходы, которые будут инвестированы в данный проект, пойдут в счет уплаты за кредиты, будут инвестированы в другой проект и т.д.).

\section{Литература}

1. Корбетт Т. Управленческий учет по ТОС/ Пер. с англ. - Киев: НіД, 2009. - 240 с.

2. Goldratt E. What is this thing called the theory of constraints and how should it be implemented? - Croton-on-Hudson: North River Press, 1990.

3. Наумов А.А., Максимов М.А. Управление экономическими системами. Процессный подход. - Новосибирск: ОФСЕТ, 2008. - 300 с. 